\section{Doppler Imaging and Histology of the Synovium}

\section{To the Editor:}

It is possible to examine the inflammation of a joint, bursa, or tendon area with ultrasonography (US) using greyscale or Doppler imaging ${ }^{1}$. The detection of perfusion in synovium is a relatively new phenomenon in rheumatology and the detection of a Doppler signal in the synovium is also thought to reflect the inflammatory state ${ }^{2}$. Rheumatoid synovium is imaged by using color Doppler or power Doppler modes. The latter is thought to be better suited for depicting slow flows ${ }^{3}$, although there is an article in the literature showing no big difference between these modes ${ }^{4}$.

The aim of this report is to consider what a positive or negative power Doppler signal in the synovium means, especially in terms of histological data. And as well, to raise a question: have we thought too much of anatomy, i.e., the number of vessels (angiogenesis) in Doppler imaging, instead of explaining the existence or absence of Doppler signal with changes of flow (perfusion) in healthy and diseased synovium?

In the rheumatoid synovium the thickness of synovial lining hyperplasia, number of vessels, and stage of inflammation of the synovium correlate positively with each other, and the number of vessels is increased ${ }^{5}$. The question is whether the angiogenesis of the synovitis is the cause or consequence ("chicken or egg") 6 . Another study with 44 synovial biopsies in patients with inflammatory joint diseases also showed that the number of vessels correlated positively with the inflammatory state of the synovium $r=0.629, p<0.01$; this statistic was not shown in the original report) ${ }^{7}$. However, the number of vessels did not correlate with the amount of Doppler signal. This was surprising, and so was the finding that the amount of Doppler signal and the histological score of synovitis did not correlate statistically in any significant way. However, when there was a Doppler signal in the synovium there was always a histological inflammation or a related condition in a joint of a patient with clinically suspected synovitis. This study was carried out by a sonographer and 17 video readers of the cases, none of whom determined a positive correlation with the histological inflammation of the synovium ${ }^{8}$. Further, it was noted that the existence of Doppler signal in the synovium was not specific for inflammation. Other phenomena, such as forming fibrosis, could also give a positive Doppler signal in the synovium. Indeed, Walther, et al have pointed out in their 2 reports that there was a positive correlation between the number of vessels and amount of Doppler signal ${ }^{9,10}$. Unfortunately, they did not report the inflammatory stage of the synovium. They had 28 patients with osteoarthritis and only 19 patients with rheumatoid arthritis ${ }^{9,10}$. A fourth report on the relationship between Doppler imaging and histology showed no positive correlation between the number of synovial vessels and amount of Doppler signal ${ }^{4}$. The vascular endothelial growth factor could also be assumed to correlate positively with the amount of Doppler signal, but this was not the case in 1 study ${ }^{11}$. But why does the amount of Doppler signal not seem necessarily to correlate positively with the number of synovial vessels and the stage of histological inflammation in all the studies?

The amount of Doppler signal does not correlate with the number of synovial vessels but it does correlate with the perfusion, i.e., the stage of congestion (hyperemia) in the tissue (hypothesis). Doppler imaging is physics. The regulation of synovial perfusion is largely unknown. Strong perfusion (i.e., Doppler signal) seems to stand in relation with the acute phase of chronic joint inflammation or other factors such as overuse in healthy persons. Thus clinical arthritis (swelling, tenderness, heat) and the amount of Doppler signal correlate positively ${ }^{12}$. We also found that the Doppler signal and polymorphonuclear leukocytes, as well as the amount of fibrin, had a positive correlation ${ }^{8}$. A change in perfusion explains why cooling a joint diminishes the amount of Doppler signal ${ }^{13}$, and why Doppler signal appears in the Achilles tendon in a healthy person after running exercise ${ }^{14}$. If a glucocorticoid injection is given into a joint with Doppler signal, the signal diminishes in a few days ${ }^{15}$. Have the vessels decreased so rapidly? Hardly. It must be the decrease of perfusion that matters. In the evaluation of a synovial Doppler signal one must take into account the settings of the equipment and the "blooming phenomenon" that exaggerates perfusion ${ }^{16}$. US is an observer-dependent investigation, although relatively good results concerning the evaluation of Doppler signal have been obtained in reliability studies ${ }^{8,17,18,19}$

US can show a negative Doppler signal in histologically confirmed chronic synovitis ${ }^{7}$. There are several reasons for the absence of the Doppler signal in a rheumatoid joint. The acquisition of the image is important. The scanning planes and the position of the joint may influence the results. Excessive pressure on the probe by the sonographer ${ }^{20}$ or internal pressure in a very full joint can stop the flow. The settings of the US equipment are complicated and must be done so that the device reveals the slowest possible flows ${ }^{16}$. We have used a flow "phantom" to examine a variety of US instruments and noticed that different instruments show slow flows differently. Even different probes of the same instrument can give different results ${ }^{7}$ (unpublished data)

We know from histological research on chronic synovitis that there are more vessels per joint than in a healthy joint, but the vessels are in fact less dense and are located deeper ${ }^{21}$. Although the vessels are more dense in a healthy joint, we see perfusion with Doppler US less often ${ }^{22}$. In a resting normal joint there is no physiological demand for hyperperfusion. There is a disproportion in the chronic synovial tissue between the need for oxygen and the amount of tissue ${ }^{23}$. Thus, in some chronic cases a negative Doppler signal could be explained by the extreme hypoperfusion (vita minima). It has been shown that a very early phase of rheumatoid synovitis exhibits histological inflammation but not yet vascular proliferation ${ }^{24}$. The Doppler signal is also negative with early septic arthritis ${ }^{25}$. Intravenous microbubble contrast agents have been found to improve the detection of intraarticular vascularization in the finger joints in healthy as well as diseased joints ${ }^{26,27}$. Three-dimensional US imaging shows more Doppler signal than 2-dimensional imaging ${ }^{28}$.

The existence or nonexistence of Doppler signal in the synovium is inevitably a complicated issue. In light of present knowledge it is hard to say that the amount of Doppler signal correlates with the activity of histological synovitis. In other words, an estimation of the inflammatory stage using only the Doppler imaging mode (as nonexistent, mild, moderate, or severe) can be misleading. Detection of Doppler signal in the synovium of a patient is, however, a useful sign because it shows that the patient has some sort of an inflammation (when rare cases such as tumors have been excluded). A positive Doppler signal in the synovium may also enable a prediction of outcome $\mathrm{e}^{29,30,31}$, and a diminishing Doppler signal correlates with other markers of healing ${ }^{32}$. Doppler signal in the synovium is not specific for inflammation. It can also be found in other situations, such as forming fibrosis, as well as in a healthy synovium.

The goal of current treatment of rheumatoid arthritis is remission ${ }^{33}$. The lack of Doppler signal in the synovium of a patient does not guarantee that there is no inflammation. In "sonographic remission," greyscale findings should be normal. We need more research to understand the relationship between the histological inflammation and Doppler signal in the synovium. Perhaps we have concentrated too much on anatomy, i.e., the number of vessels (angiogenesis) in Doppler imaging. Moreover, the regulation of synovial perfusion in relation to Doppler signal deserves attention.

JUHANI M. KOSKI, MD, PhD, Consulting Rheumatologist, Kaurakuja 5, 50500 Mikkeli, Finland. Address correspondence to Dr. Koski; E-mail: f.koski@fimnet.fi

\section{REFERENCES}

1. Brown AK. Using ultrasonography to facilitate best practice in diagnosis and management of RA. Nat Rev Rheumatol 2009;5:698-706.

2. Newman JS, Adler RS, Bude RO, Rubin JM. Detection of soft-tissue hyperemia: Value of power Doppler sonography. AJR Am J Roentgenol 1994;163:385-9.

3. Martinoli C, Derchi LE, Rizzatto G, Solbiati L. Power Doppler sonography: General principles, clinical applications and future prospects. Eur Radiol 1998;8:1224-35. 
4. Schmidt WA, Volker L, Zacher J, Schlafke M, Ruhnke M, Gromnica-Ihle E. Colour Doppler ultrasonography to detect pannus in knee joint synovitis. Clin Exp Rheumatol 2000;18:439-44.

5. Rooney M, Condell D, Quinlan W, Daly L, Whelan A, Feighery C, et al. Analysis of the histologic variation of synovitis in rheumatoid arthritis. Arthritis Rheum 1988;31:956-63.

6. Paleolog EM. The vasculature in rheumatoid arthritis: Cause or consequence? Int J Exp Pathol 2009;90:249-61.

7. Koski J, Saarakkala S, Helle M, Hakulinen U, Heikkinen JO, Hermunen H. Power Doppler US and synovitis: Correlating ultrasound imaging with histopathological findings and evaluating the performance of US equipment. Ann Rheum Dis 2006;65:1590-5.

8. Koski J, Saarakkala S, Helle M, Hakulinen U, Heikkinen JO, Hermunen $\mathrm{H}$, et al. Assessing the intra- and inter-reader reliability of dynamic ultrasound images in power Doppler ultrasonography. Ann Rheum Dis 2006;65:1658-60.

9. Walther M, Harms H, Krenn V, Radke S, Faehndrich T-P, Gohlke F. Correlation of power Doppler sonography with vascularity of the synovial tissue of the knee joint in patients with osteoarthritis and rheumatoid arthritis. Arthritis Rheum 2001;44:331-8.

10. Walther M, Harms H, Krenn V, Radke S, Kirschner S, Gohlke F. Synovial tissue of the hip at power Doppler US: Correlation between vascularity and power Doppler US signal. Radiology 2002;225:225-31

11. Strunk J, Heineman E, Neeck G, Schmidt KL, Lange U. A new approach to studying angiogenesis in rheumatoid arthritis by means of power Doppler ultrasonography and measurement of serum vascular endothelial growth factor. Rheumatology 2004;43:1480-3.

12. Hau M, Schultz H, Tony HP, Keberle M, Jahns R, Haerten R, et al. Evaluation of pannus and vascularization of the metacarpophalangeal and proximal interphalangeal joints in rheumatoid arthritis by high-resolution ultrasound (multidimensional linear array). Arthritis Rheum 1999;42:2303-8.

13. Strunk J, Strube K, Klingenberger P, Müller-Ladner U, Lange U. Two- and three-dimensional Doppler sonographic evaluation of the effect of local cryotherapy on synovial perfusion in wrist arthritis. Rheumatology 2006;45:637-40.

14. Boesen MI, Koenig MJ, Torp-Pedersen S, Bliddal H, Langberg H. Tendinopathy and Doppler activity: The vascular response of the Achilles tendon to exercise. Scand J Med Sci Sports 2006;16:463-9.

15. Newman JS, Laing TJ, McCarthy CJ, Adler RS. Power Doppler sonography of synovitis: Assessment of therapeutic response - preliminary observations. Radiology 1996;198:582-4.

16. Torp-Pedersen ST, Terslev L. Setting and artefacts relevant in colour/power Doppler ultrasound in rheumatology. Ann Rheum Dis 2008;67:143-9.

17. Scheel AK, Schmidt WA, Hermann KG, Bruyn GA, D'Agostino MA, Grassi W, et al. Interobserver reliability of rheumatologists performing musculoskeletal ultrasonography: Results from a EULAR “Train the trainers" course. Ann Rheum Dis 2005;64:1043-9.

18. D'Agostino M, Wakefield RJ, Filippucci E, Backhaus M, Balint P, Bouffard J, et al. Intra- and inter-observer reliability of ultrasonography for detecting and scoring synovitis in rheumatoid arthritis: A report of a EULAR ESCISIT task force. Ann Rheum Dis 2005;64 Suppl III:62.
19. Naredo E, Möller I, Moragues C, de Agustín JJ, Scheel AK, Grassi $\mathrm{W}$, et al. Inter-observer reliability in musculoskeletal ultrasonography: Results from a "Teach the teachers" rheumatologist course. Ann Rheum Dis 2006;65:14-9.

20. Joshua F, de Carle R, Rayment M, Bryant C, Shnier R, Edmonds J, et al. Power Doppler 'blanching' after the application of transducer pressure. Australas Radiol 2005;49:218-21.

21. Stevens CR, Blake DR, Merry P, Revell PA, Levick JR. A comparative study by morphometry of the microvasculature in normal and rheumatoid synovium. Arthritis Rheum 1991;34:1508-13

22. Terslev L, Torp-Pedersen S, Qvistgaard E, von der Recke P, Bliddal $\mathrm{H}$. Doppler ultrasound findings in healthy wrists and finger joints. Ann Rheum Dis 2004;63:644-8.

23. Walsh DA, Wade M, Mapp PI, Blake DR. Focally regulated endothelial proliferation and cell death in human synovium. Am J Pathol 1998;152:691-702.

24. FitzGerald O, Soden M, Yanni G, Robinson R, Bresnihan B. Morphometric analysis of blood vessels in synovial membranes obtained from clinically affected and unaffected knee joints of patients with rheumatoid arthritis. Ann Rheum Dis 1991;50:792-6.

25. Strouse PJ, DiPietro MA, Adler RS. Pediatric hip effusions: evaluation with power Doppler sonography. Radiology 1998;206:731-5.

26. Terslev L, Torp-Pedersen S, Bang N, Koenig MJ, Nielsen MB, Bliddal H. Doppler ultrasound findings in healthy wrists and finger joints before and after use of two different contrast agents. Ann Rheum Dis 2005;64:824-7.

27. Klauser A, Frauscher F, Schirmer M, Halpern E, Pallwein L, Herold M, et al. The value of contrast-enhanced color Doppler ultrasound in the detection of vascularization of finger joints in patients with rheumatoid arthritis. Arthritis Rheum 2002;46:647-53.

28. Strunk J, Lange U. Three-dimensional power Doppler sonographic visualization of synovial angiogenesis in rheumatoid arthritis. J Rheumatol 2004;31:1004-6.

29. Taylor PC, Steuer A, Gruber J, Cosgrove DO, Blomley MJ, Marsters PA, et al. Comparison of ultrasonographic assessment of synovitis and joint vascularity with radiographic evaluation in a randomized, placebo-controlled study of infliximab therapy in early rheumatoid arthritis. Arthritis Rheum 2004;50:1107-16.

30. Naredo E, Collado P, Cruz A, Palop MJ, Cabero F, Richi P, et al. Longitudinal power Doppler ultrasonographic assessment of joint inflammatory activity in early rheumatoid arthritis: predictive value in disease activity and radiologic progression. Arthritis Rheum 2007:57:116-24.

31. Brown AK, Conaghan PG, Karim Z, Quinn MA, Ikeda K, Peterfy $\mathrm{CG}$, et al. An explanation for the apparent dissociation between clinical remission and continued structural deterioration in rheumatoid arthritis. Arthritis Rheum 2008;58:2958-67.

32. Naredo E, Möller I, Cruz A, Carmona L, Garrido J. Power Doppler ultrasonographic monitoring of response to anti-tumor necrosis factor therapy in patients with rheumatoid arthritis. Arthritis Rheum 2008;58:2248-56.

33. Smolen JS, Aletaha D, Bijlsma WJ, Breedveld C, Boumpas D, Burmester G, et al. Treating rheumatoid arthritis to target: Recommendations of an international task force. Ann Rheum Dis 2010;69:631-7.

J Rheumatol 2012:39;2; doi:10.3899/jrheum.110814 